Notes \& Tips

\title{
Short homologies efficiently generate detectable homologous recombination events
}

\author{
Andrew N. Osahor ${ }^{\mathrm{a}, \mathrm{b}}$, Chau-Yan Tan ${ }^{\mathrm{a}}$, Edmund Ui-Hang Sim ${ }^{\mathrm{c}}$, Choon-Weng Lee ${ }^{\mathrm{d}}$, Kumaran Narayanan ${ }^{\mathrm{a}, \mathrm{e}, *}$ \\ ${ }^{a}$ School of Science, Monash University Malaysia, 46150 Bandar Sunway, Selangor, Malaysia \\ ${ }^{\mathrm{b}}$ Department of Biotechnology, Malaysia University of Science and Technology, 47301 Petaling Jaya, Selangor Darul Ehsan, Malaysia \\ ${ }^{\mathrm{c}}$ Department of Molecular Biology, Faculty of Resource Science and Technology, Universiti Malaysia Sarawak, 94300 Kota Samarahan, Sarawak, Malaysia \\ ${ }^{\mathrm{d}}$ Laboratory of Microbial Ecology, Institute of Biological Sciences, University of Malaya, 50603 Kuala Lumpur, Malaysia \\ ${ }^{\mathrm{e}}$ Department of Genetics and Genomic Sciences, Icahn School of Medicine at Mount Sinai, New York, NY 10029, USA
}

\section{A R T I C L E I N F O}

\section{Article history:}

Received 6 May 2014

Received in revised form 29 May 2014

Accepted 30 May 2014

Available online 11 June 2014

\section{Keywords:}

BACs

E. coli

Homology

Recombineering

Linear

Chromosome

\begin{abstract}
A B S T R A C T
When recombineering bacterial artificial chromosomes (BACs), it is common practice to design the ends of the donor molecule with $50 \mathrm{bp}$ of homology specifying its insertion site. We demonstrate that desired recombinants can be produced using intermolecular homologies as short as $15 \mathrm{bp}$. Although the use of shorter donor end regions decreases total recombinants by several fold, the frequency of recombinants with correctly inserted donor molecules was high enough for easy detection by simple polymerase chain reaction (PCR) screening. This observation may have important implications for the design of oligonucleotides for recombineering, including significant cost savings, especially for high-throughput projects that use large quantities of primers.
\end{abstract}

(c) 2014 Elsevier Inc. All rights reserved.
Homologous recombination has grown to become important for developing novel genetic engineering tools for functional genomics, including for genetic repair of mutated DNA and for re-creating specific mutations in cell and animal models. There has been remarkable progress in our understanding of the recombination systems of Escherichia coli and its phages, which has permitted their controlled use for direct DNA engineering in E. coli [1-3].

It is well established that the efficiency of homologous recombination in $E$. coli increases correspondingly with the increasing homology sequences [4]. For example, a 50-bp homology is able to generate approximately 150 recombinants $/ 10^{8}$ viable cells, and when the homology was increased to $140 \mathrm{bp}$, more than 1000 recombinants $/ 10^{8}$ viable cells were obtained [5]. But once the homology exceeds $500 \mathrm{bp}$, there is no further increase observed in recombination efficiency [6].

Previous research has shown that to obtain detectable homologous recombination between linear donor and circular/linear recipient substrates, a homology of approximately $50 \mathrm{bp}$ is required at both ends of the DNA $[1,3]$. The effects of using shorter homologies are not well established and are generally anecdotal in nature [4],

\footnotetext{
* Corresponding author at: School of Science, Monash University Malaysia, 46150 Bandar Sunway, Selangor, Malaysia. Fax: +60 355146364.

E-mail address: kumaran.narayanan@monash.edu (K. Narayanan).
}

resulting in a gap in our understanding of the requirements for donors and recipients in homologous recombination. However, it is generally accepted that shorter homologies are likely to produce too few colonies, resulting in difficulty in detecting and identifying recombinants.

Based on our existing understanding about recombineering, because $50 \mathrm{bp}$ can give hundreds of recombinants-much more than necessary-we hypothesized that shorter homologies would still give enough recombinants that are detectable and allow creation of desired modifications. The notion that shorter homologies could work was reinforced when we observed detectable recombination between a short unequal homology pair of 31 and 24 bp by sheer serendipity in our laboratory (not shown).

In this work, we tested this hypothesis by systematically measuring the recombination of a linear donor DNA containing an 816-bp kanamycin resistance $\left(\mathrm{Km}^{\mathrm{r}}\right)^{1}$ cassette with decreasing lengths of flanking homology into a linear bacterial artificial chromosome (BAC) target, pBelo-tos [3,7]. This linear BAC replicates as a stable plasmid with hairpin telomeres in $E$. coli and is used as a recipient in this work $[3,7]$.

\footnotetext{
Abbreviations used: $\mathrm{Km}^{\mathrm{r}}$, kanamycin resistance; BAC, bacterial artificial chromosome; PCR, polymerase chain reaction; $\mathrm{Cm}$, chloramphenicol; $\mathrm{Km}$, kanamycin; $\mathrm{Cm}^{\mathrm{r}}$, chloramphenicol resistance; nt, nucleotide.
} 